\title{
Optimal portfolio choices using financial leverage
}

\author{
Ricardo Laborda, Centro Universitario de la Defensa de Zaragoza \\ Jose Olmo, University of Southampton
}

\begin{abstract}
This paper investigates the role of leverage in determining the investor's optimal asset allocation over multiperiod investment horizons. To do this, we allow investors to lever their financial position by borrowing from credit markets. GMM methods are used to estimate and test the optimal portfolio weights and individual's optimal choice of financial leverage. These optimal choices are assumed to be parametric functions of a set of state variables describing the evolution of the economy. The empirical application of this methodology to a portfolio of cash, bonds and stocks reveals that a) financial leverage limits the reaction of investors to changes in the investment opportunity set; b) individuals increase leverage during recessions and deleverage in expansionary periods; c) optimal portfolio weights and financial leverage are negatively related to the degree of investor's risk aversion and positively related to the investment horizon.
\end{abstract}

Key words: financial leverage; gmm estimation and testing; long-term optimal asset allocation; portfolio theory

JEL Codes: E32, E52, E62, G01.

${ }^{*}$ Corresponding Address: School of Social Sciences, Department of Economics, University of Southampton, Room 3015, Bld 58 (Murray Bld), Highfield Campus, Southampton, SO17 1BJ, UK. Phone: (+44) $2380595000 . \quad$ E-mail address: J.B.Olmo@soton.ac.uk. 


\section{Introduction}

Optimal portfolio decisions depend on the environment faced by investors. This is mainly characterized by the investment opportunity set, which is related to the set of financial assets and their asset return distributions, investor's preferences and the information available to the individual. There are other features, usually overlooked, that also influence optimal portfolio decisions such as the investment horizon, the existence of non-traded assets such as human capital, the availability of illiquid assets such as housing, taxation or the presence of credit markets expanding investors' resources and investment possibilities, see Campbell (2006) for a detailed analysis of household finance.

The last forty years have witnessed the development of sound credit markets providing access to funding to individuals and boosting consumption, investment and stock markets. The importance of the leverage of an economy to the formation of asset prices and the development of economic cycles has become even more evident since the 2007-2009 crisis, especially through the leverage of financial intermediaries and the financial sector, see Shularick and Taylor (2012), He and Krishnamurthy (2013) and Brunnermeier and Sannikov (2014), among many others. During boom times investors had the possibility of partially funding their portfolios through leveraged borrowing in the form of uncollateralized loans and overvalued collateral, bidding stock prices up. During bad times the above process reversed affecting adversely asset prices dynamics. The ability of investors to borrow against their own depreciated assets was also affected compromising the realization of their investment objectives. It is therefore of interest to understand not only whether the availability of credit markets can increase stock prices through financial leverage but also whether investors' risk attitudes and optimal portfolio decisions effectively change as a result of fluctuations in the access to credit markets produced by the occurrence of business cycles. The effect of credit markets on optimal portfolio decisions can also depend on the choice of investment horizon as short-investment horizons are bound to be less sensitive to borrowing conditions and business cycle dynamics than long-term horizons.

The aim of this study is to assess the role of financial leverage in establishing the optimal asset allocation of investors with multiperiod investment horizons. To do this, we entertain two different scenarios. First, we analyze the optimal portfolio decision of an individual that has access to credit 
markets but faces a borrowing constraint. In this scenario the individual's leverage position cannot be optimized as it is determined exogenously by the lender. The second scenario corresponds to an individual that can optimally choose the amount of leverage in each period. In order to make the problem analytically tractable, we consider the individual's leverage to be a parametric function of the business cycle. Thus individual's leverage is allowed to exhibit positive or negative commovements with economic conditions depending on the sign and magnitude of the model parameters driving the parametric relationship between individual's leverage and the business cycle. There are numerous parametric functions that can be chosen to assess such relationship. Our choice is informed by the elasticity of the individual's leverage with respect to its exposure to the business cycle. This elasticity is defined as the product of a linear and a logit factor such that the first factor determines the cyclicality of individual's leverage with respect to the business cycle and the second factor its curvature.

Optimal asset allocation for multiperiod investment horizons is analytically complex but can be resolved by numerical methods, see Brennan et al. (1997, 1999), or approximate solutions as in Campbell and Viceira (1999, 2001, 2002). Brandt (1999), Aït-Sahalia and Brandt (2001) and Brandt and Santa-Clara (2006) offer, instead, an alternative strategy based on the direct estimation of the optimal portfolio weights. These weights are modeled as a parametric linear function of a set of relevant state variables that drive the changes in the time-varying investment opportunity set. In this paper, we follow a similar strategy for modelling the dynamics of the optimal portfolio weights over an investment horizon that spans several periods. By doing so, we convert a complex multiperiod maximization exercise into an analytically tractable problem but sufficiently flexible to analyze the effect of financial leverage on optimal asset allocation decisions. Estimation of the model parameters determining the optimal asset allocation and individual's optimal leverage position is done using the generalized method of moments applied to an overidentified set of Euler equations characterising the first order conditions of the investor's multiperiod optimization problem.

Our empirical analysis for a portfolio of stocks, bonds and cash reveals that increases on investor's financial leverage lower, in absolute value, the exposure of the risky assets to the state variables, and therefore, the magnitude of the allocation to risky assets in the optimal portfolio choice. This finding 
is interpreted as empirical evidence of a reduction in the responsiveness of the optimal portfolio weights to changes in the state variables, preventing individuals from engaging in very aggressive portfolio allocations even if the state variables can be anticipating an improvement of the investment opportunity set. The empirical analysis also reveals that when individuals are allowed to optimize their leverage position with respect to the business cycle they choose countercyclical policies: increasing leverage during recessions and decreasing it during economic expansions. We also observe a more aggressive reaction of the optimal leverage position to the economic environment as the degree of relative risk aversion falls and the investment horizon increases.

The rest of the article is structured as follows. Section 2 introduces the multiperiod optimal asset allocation problem for portfolios that can be levered by borrowing from credit markets. Section 3 discusses suitable econometric methods to estimate the model parameters and presents a statistical test to assess the correct specification of the parametric portfolio policy rule and the functional form of the individual's leverage position. Section 4 presents an application to a portfolio of stocks, bonds and cash to empirically assess the relationship between the long-term optimal portfolio allocation, the individual's financial leverage position, the coefficient of relative risk aversion and the individual's investment horizon. Section 5 concludes.

\section{The Model}

We are concerned with the investment decision of an agent who maximizes the expected utility of wealth $\left(w_{t}\right)$ over a multiperiod investment horizon. Assume that the multiperiod utility function is additively time separable and exhibits constant relative risk aversion. An investor maximizes

$$
\sum_{j=0}^{K} \beta^{j} E_{t}\left[\frac{w_{t+j}^{1-\gamma}}{1-\gamma}\right]
$$

with $\gamma>0, \gamma \neq 1, K$ is an arbitrarily large number denoting the number of periods considered in the optimal investment plan, $\beta$ is the time-preference parameter and $\gamma$ the risk aversion coefficient.

The availability of credit markets implies that the investor can lever its financial position and 
increase its allocation to stocks in the investment portfolio. More specifically, let $\widetilde{w}_{t}=w_{t}+b_{t}$ be the individual's financial wealth in each period and $r_{p, t}$ the return on the investment portfolio, defined as

$$
r_{p, t}\left(\alpha_{t-1}\right)=r_{f, t}+r_{e, t}^{p}\left(\alpha_{t-1}\right)
$$

with $r_{e, t}^{p}\left(\alpha_{t-1}\right)=\alpha_{t-1}^{\prime} r_{e, t}$, where $r_{e, t}=\left(r_{1, t}-r_{f, t}, \ldots, r_{m, t}-r_{f, t}\right)^{\prime}$ is the vector of excess returns on the $m$ risky assets and $\alpha_{t}=\left(\alpha_{1, t}, \ldots, \alpha_{m, t}\right)$ determines the allocation to stocks in the portfolio. The wealth (equity) obtained by the investor in each period, denoted by $w_{t}$, is the result of its portfolio allocation in the preceding period net of last period's debt $\left(b_{t-1}\right)$. Further, in this model debt is fully repaid at the end of each period at an interest rate $r_{b, t}$. More formally, the wealth process is

$$
\widetilde{w}_{t-1}\left(1+r_{p, t}\left(\alpha_{t-1}\right)\right)-b_{t-1}\left(1+r_{b, t}\right)=w_{t} .
$$

In this setup, investors finance their portfolios using their own equity as well as the proceeds of debt. Let $\eta_{t}=b_{t} / w_{t}$ denote the individual's financial leverage position, then, we can write individual's debt as a function of its leverage and financial wealth as

$$
b_{t}=f\left(\eta_{t}\right) \widetilde{w}_{t},
$$

with $f(\eta)=\eta /(1+\eta)$. The equation describing the accumulation of equity by the investor is

$$
w_{t}=\left(1+r_{t}^{e q}\left(\alpha_{t-1}, \eta_{t-1}\right)\right) w_{t-1}
$$

with

$$
r_{t}^{e q}\left(\alpha_{t-1}, \eta_{t-1}\right)=r_{p, t}\left(\alpha_{t-1}\right)+\eta_{t-1}\left(r_{p, t}\left(\alpha_{t-1}\right)-r_{b, t}\right)
$$

the return on equity. This financial return exceeds the portfolio return obtained under no leverage by including an additional return in excess of the interest rate on the loan obtained by levering the 
individual's financial position. Under these conditions, the accumulation of wealth equation becomes

$$
w_{t+j}=\prod_{i=1}^{j}\left(1+r_{t}^{e q}\left(\alpha_{t-1}, \eta_{t-1}\right)\right) w_{t} .
$$

In order to convert the individual's multiperiod maximization exercise into an analytically tractable problem we assume a parametric linear portfolio policy rule for describing the dynamics of the portfolio asset allocation. We extend the parametric methodology introduced in the contributions of Aït-Sahalia and Brandt (2001), Brandt and Santa-Clara (2006) and Brandt et al. (2009) to an arbitrarily large investment horizon. Thus

$$
\alpha_{h, t}=\lambda_{h}^{\prime} z_{t}, h=1, \ldots, m,
$$

with $z_{t}=\left(z_{1, t}, \ldots, z_{n, t}\right)^{\prime}$ a set of state variables describing the evolution of the economy and $\lambda_{h}=$ $\left(\lambda_{h, 1}, \ldots, \lambda_{h, n}\right)^{\prime}$ the corresponding vector of parameters ${ }^{1}$.

The individual's maximization problem (1) depends on whether the investor exhibits an exogenous leverage position or chooses it optimally. In the first case we assume financial leverage to be given, and use $r_{t}^{e q}(\lambda)$ to denote the return on equity. In this setup, the individual's maximization problem (1) is with respect to $\lambda$ :

$$
\max _{\{\lambda\}}\left\{\sum_{j=1}^{K} \beta^{j} \frac{w_{t}^{1-\gamma}}{1-\gamma} E_{t}\left[\left(\prod_{i=1}^{j}\left(1+r_{t+i}^{e q}(\lambda)\right)\right)^{1-\gamma}\right]\right\} .
$$

The first order conditions of this optimization problem with respect to the vector of parameters $\lambda_{h s}$, with $h=1, \ldots, m$ and $s=1, \ldots, n$ provide the following system of $m n$ Euler equations:

$$
E_{t}\left[\sum_{j=1}^{K} \beta^{j} \psi_{t, j}\left(z_{s}, \lambda_{h}\right)\right]=0
$$

\footnotetext{
${ }^{1}$ This specification of the portfolio weights has two main features. First, it allows us to study the marginal effects of the state variables on the optimal portfolio weights through the set of parameters $\lambda$, and second, it avoids the introduction of time consuming dynamic stochastic programming methods. A potential downside of this parametric approach is to force the individual's optimal portfolio policy rule to be linear and with the same parameter values over the long-term horizon. Nevertheless, for finite horizon $(K<\infty)$ objective functions, more sophisticated models can be developed that entertain horizon-specific parametric portfolio policy rules. This approach significantly increases the computational complexity of the methodology and is beyond the scope of this paper.
} 
with

$$
\psi_{t, j}\left(z_{s}, \lambda_{h}\right)=\left(\sum_{i=1}^{j} \frac{\left(1+\eta_{t+i-1}\right) z_{s, t+i-1} r_{h, t+i}^{e}}{1+r_{t+i}^{e q}(\lambda)}\right)\left(\prod_{i=1}^{j}\left(1+r_{t+i}^{e q}(\lambda)\right)\right)^{1-\gamma}
$$

For the second case, we propose a flexible parametric specification of the leverage position that can accommodate procyclical and countercyclical behaviors with respect to the business cycle, denoted hereafter by $y_{t}$. More specifically, we focus on modeling the elasticity of the individual's leverage position with respect to its exposure to the business cycle $(\kappa)$ as a function of the ratio $\frac{\kappa y_{t}}{\eta_{t}}$ scaled by a logit function. Mathematically,

$$
\frac{\partial \eta_{t} / \eta_{t}}{\partial \kappa / \kappa}=\frac{\kappa y_{t}}{\eta_{t}} \frac{1}{1+\exp \left(-\kappa y_{t}\right)}
$$

The factor $\kappa y_{t} / \eta_{t}$ drives a procyclical (positive) relationship between the leverage parameter and the business cycle if the parameter $\kappa$ is positive and a countercyclical (negative) relationship, otherwise. The logit function is a scale function in the $[0,1]$ interval that determines the curvature of the elasticity of the individual's leverage with respect to the business cycle contribution $\left(\kappa y_{t}\right)$. Interestingly, the above functional form for the elasticity of leverage with respect to the exposure to the business cycle yields a simple expression for the individual's financial leverage position:

$$
\eta_{t}=\ln \left(1+\exp \left(\kappa y_{t}\right)\right)
$$

The parameter $\kappa$ is a decision variable optimally chosen by the investor that determines whether its leverage is procyclical or countercyclical with respect to the business cycle. In this framework, the individual's return on equity (6) is defined in terms of the decision parameters $(\lambda, \kappa)$, and the corresponding maximization problem (1) is

$$
\max _{\{\lambda, \kappa\}}\left\{\sum_{j=1}^{K} \beta^{j} \frac{w_{t}^{1-\gamma}}{1-\gamma} E_{t}\left[\left(\prod_{i=1}^{j}\left(1+r_{t+i}^{e q}(\lambda, \kappa)\right)\right)^{1-\gamma}\right]\right\}
$$

The first order conditions of this optimization problem with respect to the vector of parameters $\lambda_{h s}$, 
with $h=1, \ldots, m$ and $s=1, \ldots, n$ provide the following system of $m n$ Euler equations:

$$
E_{t}\left[\sum_{j=1}^{K} \beta^{j} \psi_{t, j}\left(z_{s}, \lambda_{h}\right)\right]=0
$$

with

$$
\psi_{t, j}\left(z_{s}, \lambda_{h}\right)=\left(\sum_{i=1}^{j} \frac{\left(1+\eta_{t+i-1}\right) z_{s, t+i-1} r_{h, t+i}^{e}}{1+r_{t+i}^{e q}(\lambda, \kappa)}\right)\left(\prod_{i=1}^{j}\left(1+r_{t+i}^{e q}(\lambda, \kappa)\right)\right)^{1-\gamma}
$$

and $\eta_{t+i-1}$ driven by (13).

The possibility of choosing the optimal amount of leverage in the financial position entails an additional set of Euler equations obtained from maximizing the individual's objective function with respect to $\kappa$ :

$$
E_{t}\left[\sum_{j=1}^{K} \beta^{j} \psi_{t, j}^{\kappa}(y)\right]=0
$$

with

$$
\psi_{t, j}^{\kappa}(y)=\left(\sum_{i=1}^{j} \frac{y_{t+i-1}\left(r_{t+i}^{p}\left(\lambda_{h}^{\prime} z_{t+i-1}\right)-r_{b, t+i}\right)}{\left(1+\exp \left(-\kappa y_{t+i-1}\right)\right)\left(1+r_{t+i}^{e q}(\lambda, \kappa)\right)}\right)\left(\prod_{i=1}^{j}\left(1+r_{t+i}^{e q}(\lambda, \kappa)\right)\right)^{1-\gamma} .
$$

The introduction of the vector of state variables $z_{t}$ into the specification of the allocation of assets to the portfolio allows us to incorporate forecasts of the investment opportunity set in the optimal asset allocation. These results can be refined by observing that the set of conditions (15) and (17) can be expressed in terms of an augmented set of unconditional expectations. To do this we need to assume that the conditioning information set determining the above conditional expectations is fully described by the vector $z_{t}=\left(z_{1, t}, z_{2, t}, \ldots, z_{n, t}\right)^{\prime}$ of state variables with $z_{1, t}=1$ and the rest of state variables being a set of $n-1$ macroeconomic and financial variables. Relevant examples of this estimation strategy applied to asset pricing and optimal portfolio theory can be found in Cochrane (1996) and Aït-Sahalia and Brandt (2001), among many others. Under these conditions, we have

$$
E\left[\sum_{j=1}^{K} \beta^{j} \psi_{t, j}\left(z_{s}, \lambda_{h}\right) \otimes z_{t}\right]=0
$$


and

$$
E\left[\sum_{j=1}^{K} \beta^{j} \psi_{t, j}^{\kappa}(y) \otimes z_{t}\right]=0
$$

where $\otimes$ denotes element by element multiplication.

\section{Econometric methods}

This section discusses the empirical implementation of the optimality conditions derived in the preceding section. To do this we propose a simple econometric methodology for the estimation of the set of parameters $\lambda$ and $\kappa$ driving the optimal portfolio weights and leverage dynamics. The section also discusses inference procedures to test the correct specification of the parametric portfolio policy (8) and the parametric form of the function (13) driving the dynamics of the leverage parameter.

\subsection{Estimation}

Expressions (19) and (20) describe a system of $(m n+1) n$ Euler equations. These equations can be used to estimate the optimal portfolio weights characterized by the set of parameters $\lambda$ and the optimal leverage position characterized by the vector $\kappa$. GMM is a natural econometric technique to estimate $(m+1) n$ parameters using $(m n+1) n$ equations. A suitable empirical representation of the above system of Euler equations is

$$
\widehat{\phi}_{h, s}\left(z_{s}, \lambda_{h}\right)=\frac{1}{T-K} \sum_{t=1}^{T-K}\left(\sum_{j=1}^{K} \beta^{j} \psi_{t, j}\left(z_{s}, \lambda_{h}\right) \otimes z_{t}\right)=0
$$

and

$$
\widehat{\phi}_{\kappa}(y, \kappa)=\frac{1}{T-K} \sum_{t=1}^{T-K}\left(\sum_{j=1}^{K} \beta^{j} \psi_{t, j}^{\kappa}(y) \otimes z_{t}\right)=0
$$


where $T$ is the sample size used for estimating the model parameters. For each pair $(h, s)$, condition (21) yields a $n \times 1$ vector of moment conditions denoted as

$$
\widehat{\phi}_{h, s}^{(\widetilde{s})}\left(z_{s}, \lambda_{h}\right)=\frac{1}{T-K} \sum_{t=1}^{T-K}\left(\sum_{j=1}^{K} \beta^{j} \psi_{t, j}\left(z_{s}, \lambda_{h}\right) z_{\widetilde{s}, t}\right)
$$

with $\widetilde{s}=1, \ldots, n$ where $z_{1, t}=1$. Similarly, condition $(22)$ yields a $n \times 1$ vector, $\widehat{\phi}_{\kappa}^{(\widetilde{s})}$, of moment conditions describing the empirical counterpart of the first order conditions (20) with respect to the parameter $\kappa$.

Let $g_{T}$ be the $(m n+1) n \times 1$ vector that stacks each of the sample moments $\widehat{\phi}_{h, s}^{(\widetilde{s})}$ and $\widehat{\phi}_{\kappa}^{(\widetilde{s})}$ indexed by $h, s$ and $\widetilde{s}$, with $h=1, \ldots, m$ and $s, \widetilde{s}=1, \ldots, n$. The idea behind GMM is to choose the vector $(\widehat{\lambda}, \widehat{\kappa})$ so as to make the sample moments $g_{T}$ as close to zero as possible. More formally, the GMM estimator of the vector $(\lambda, \kappa)$ is defined as

$$
(\widehat{\lambda}, \widehat{\kappa})=\underset{c_{1} \in \Lambda, c_{2} \in \kappa}{\arg \min } g_{T}\left(c_{1}, c_{2}\right)^{\prime} \widehat{V}_{T}^{-1} g_{T}\left(c_{1}, c_{2}\right)
$$

where $\widehat{V}_{T}$ is an $(m n+1) n \times(m n+1) n$, possibly random, non-negative definite weight matrix, whose rank is greater than or equal to $(m+1) n$. This matrix admits different representations. In a first stage $\widehat{V}_{T}$ can be the identity matrix or some other matrix, as for example, $I_{(m+1) n} \otimes Z^{\prime} Z$, with $I_{(m+1) n}$ the identity matrix of dimension $(m+1) n$ and $Z$ the $(T-K) \times n$ matrix corresponding to the state variables. In a second stage, to gain efficiency, this matrix is replaced by a consistent estimator of the asymptotic covariance matrix $V_{0}$ of the random vector $g_{T}\left(c_{1}, c_{2}\right)$.

\subsection{Hypothesis tests}

To statistically assess the empirical suitability of the above parametric specifications we apply the specification $J$-test proposed by Hansen (1982). This test assesses whether the estimates of the $\lambda$ and $\kappa$ parameters obtained from setting to zero $(m+1) n$ linear combinations of the $(m n+1) n$ equations conform with the rest of sample orthogonality conditions in $g_{T}\left(c_{1}, c_{2}\right)$. More specifically, the correct spec- 
ification of the model implies that there are $m n(n-1)$ linearly independent combinations of $g_{T}(\widehat{\lambda}, \widehat{\kappa})$

that should be close to zero but are not exactly equal to zero. Let $s(\widehat{\lambda}, \widehat{\kappa})=g_{T}(\widehat{\lambda}, \widehat{\kappa})^{\prime} \widehat{V}_{T}^{-1} g_{T}(\widehat{\lambda}, \widehat{\kappa})$, that under the null hypothesis of correct specification of the model, satisfies

$$
(T-K) s(\widehat{\lambda}, \widehat{\kappa}) \stackrel{d}{\rightarrow} \chi_{m n(n-1)}^{2}
$$

This test rejects the null hypothesis of correct specification of the models (8) and (13) if the test statistic is larger than the critical value obtained from a $\chi^{2}$ distribution with $m n(n-1)$ degrees of freedom. The convergence rate $T-K$ can be replaced by $T$ as $K$ is assumed to be finite throughout.

\section{Empirical application}

We focus on the optimal asset allocation of an investor with a multiperiod utility function that can lever its financial portfolio. The individual's optimal portfolio policy rule follows the parametric function (8) with respect to a set of state variables describing the evolution of the economy. This modeling strategy is implemented for $\beta=0.95$ and different parameterizations of the investor's objective function characterized by $K=12,60$ and 120 and $\gamma=2,5$ and 40 . The borrowing interest rate is assumed to be the risk-free rate.

\subsection{Descriptive analysis}

Time variation of the investment opportunity set is described by a set of state variables that have been identified in the empirical literature as potential predictors of the excess stock and bond returns and the short-term ex-post real interest rates. The set of state variables are the detrended shortterm interest rate (Campbell, 1991), the U.S. credit spread (Fama and French, 1989), the S\&P 500 trend (Aït-Sahalia and Brandt, 2001) and the one-month average of the excess stock and bond returns (Campbell et al., 2003). The detrended short-term interest rate detrends the short-term rate by subtracting a 12-month backwards moving average. The U.S. credit spread is defined as the yield difference between Moody's Baa- and Aaa-rated corporate bonds. The S\&P 500 momentum is the 
difference between the log of the current S\&P 500 index level and the average index level over the previous twelve months. We demean and standardize all the state variables in the optimization process (Brandt et al, 2009).

Our data covers the period January 1980 to December 2010. We collect monthly data from Bloomberg on the S\&P 500 and G0Q0 Bond Index. The G0Q0 Bond Index is a Bank of America and Merrill Lynch U.S. Treasury Index that tracks the performance of U.S. dollar denominated sovereign debt publicly issued by the U.S. government in its domestic market. We collect the Industrial Production Index (IPI) and Consumer Price Index (CPI) time series from the U.S. Federal Reserve and the yield of the Moody's Baa and Aaa-rated corporate bonds from the U.S. Federal Reserve. The nominal yield on the U.S. one-month risk-free rate reported in the Fama and French database is used as the risk-free rate and also as the borrowing rate on individuals' loans.

Table 1 reports the sample statistics of the annualized excess stock return, excess bond return and short-term ex-post real interest rates. Summary statistics on the S\&P 500 index are computed using the series of prices without dividends. The comparison between the corresponding bond and equity prices shows the outperformance of the bond market over the stock market during this period. In particular, the excess return on the bond index is higher than for the S\&P 500 and exhibits a lower volatility entailing a Sharpe ratio almost three times higher for bonds than stocks. Additionally, the excess bond return has larger skewness and lower kurtosis. This anomalous outperformance of the G0Q0 index versus the S\&P 500 is mainly explained by the last part of the sample and the consequences of the subprime crisis on the valuation of the different risky assets. However, as noted by a referee, this result is partly reversed if we include the dividends to the series of the S\&P 500 index.

[Insert Tables 1 to 2 about here]

Table 2 shows the estimates of the seemingly unrelated regression estimation of the excess stock return, excess bond return and short-term ex-post real interest rate using as explanatory variables the detrended short-term interest rate, the U.S. credit spread, the S\&P 500 trend and the one-month average of the excess stock and bond returns. These estimates allow us to obtain some insights on the 
dynamics of excess stock and bond returns and their variation over time linked to the state variables that we assume are driving the change in the investment opportunity set. A first conclusion that can be drawn from the estimated model, and in particular from the low $R^{2}$ statistics reported, is the difficulty in predicting excess asset returns.

\subsection{Optimal asset allocation over multiple periods}

The parameter estimates driving the optimal portfolio rules and dynamic leverage coefficients are estimated using a two-step Gauss-Newton type algorithm using numerical derivatives. In a first stage we initialize the covariance matrix $\widehat{V}_{T}$ with the matrix $I_{(m+1) n} \otimes Z^{\prime} Z$, and in a second stage, after obtaining a first set of parameter estimates, we repeat the estimation replacing this matrix by a trimmed version of the empirical covariance matrix. In particular, we use a Newey-West estimator of the matrix $V_{0}$ with $K=12$ lags.

\subsubsection{Fixed exogenous leverage}

Table 3 reports the estimates for the unconstrained case characterized by no leverage in the portfolio $(\eta=0)$. This case constitutes the base scenario given by the absence of borrowing, and hence, of borrowing frictions. To assess the robustness of the results to differences in the investment horizon, we entertain $K=12,60,120$ for a risk aversion coefficient $\gamma=5$. For simplicity, throughout the tables, we only report the parameter estimates $\lambda$ in (8) associated to the state variables and not to the intercept given by $z_{1, t}=1$. The results in Table 3 show that the optimal allocation to the S\&P 500 index is found to be positively related to the one-month average of the excess stock and bond returns and negatively related to the detrended short-term interest rate. The optimal allocation to bonds is negatively related to all of the state variables.

[Insert Table 3 about here]

The unconstrained case can be regarded as a particular case of a more general process that considers debt to be a fixed function of equity. In this scenario portfolio leverage is constant but greater than 
zero entailing a debt processes that comoves with individual's equity, that is, $b_{t}=\eta w_{t}$. Our simulation exercise with real data comprises several scenarios characterized by different values of $\eta \in(0,1)$. To assess the robustness of the results to variations in the investment horizon and risk aversion, we consider in Figures 1 to 3 the different investment strategies characterized by $\beta=0.95, K=12,60$ and 120 , and $\gamma=2,5$ and 40 .

Figure 1 plots the values of the $\lambda$ parameters associated to the risky assets in the portfolio $-S \& P$ 500 index and G0Q0 bond index - with respect to different values of the borrowing constraint for $K=120$ and $\gamma=2,5$ and 40. In order to assess the relationship between the individual's financial leverage and the optimal portfolio allocation, we consider different values of the debt ratio within the $(0,1)$ interval. The asset allocation is obtained in this case from the set of first order conditions $(15)$ (16) under the assumption that the parameter $\eta$ is constant over time. The plot reveals that increases on investor's leverage and, hence, on the amount of debt raised by the individual, lower, in absolute value, the magnitude of the $\lambda$ parameters associated to all of the state variables. Interestingly, the sign is preserved with respect to the base scenario. This result also provides evidence of a reduction in the responsiveness of the optimal portfolio weights to changes in the state variables, preventing individuals from engaging in very aggressive portfolio allocations even if the state variables could be anticipating an improvement of the investment opportunity set.

Figure 2 compares the optimal portfolio weights of an unconstrained investor, $\eta=0$, with those of a highly levered investor whose debt ratio equals $\eta=20$. The unconstrained optimal portfolio weights allocated to the S\&P 500 and G0Q0 financial indices are very volatile and react very aggressively to changes of the investment opportunity set. This is also reflected on large short positions allocated to the one-month Treasury bill to fully benefit from existing profit opportunities on risky assets. In contrast, the optimal portfolio decisions of highly levered individuals are much more moderate and yield returns close to those obtained from fully investing on the risk-free asset even in the presence of potential profit opportunities obtained from investing on risky assets.

We also investigate the role of the investment horizon on the asset allocation problem of an individual with a fixed leverage position and a risk aversion coefficient $\gamma=5$. Figure 3 plots the values 
of the $\lambda$ parameters associated to the $S \& P 500$ and G0Q0 bond indices for $K=12,60$ and 120 . The results reported in this analysis are more heterogeneous than in the preceding exercises if the comparisons are done with respect to the investment horizon. Whereas there is a monotonically increasing relationship between the magnitude of the $\lambda$ parameters and the investment horizon for almost all of the coefficients corresponding to the S\&P 500 index, this is not the case for the coefficients gauging the dynamics of the G0Q0 bond index. In some cases the sign of the parameters also varies with the investment horizon. Thus, variation in the U.S. credit spread has a positive impact on the allocation to the stock index for short investment horizons but a negative impact over longer horizons. The trend S\&P 500 state variable exhibits opposite findings; the sensitivity of the $\lambda$ parameters to variation of this state variable switches from a negative to a positive sign as the investment horizon increases.

[Insert Figures 1 to 3 about here]

The overall analysis performed so far shows that increases in individual's leverage have the same qualitative effects as increases in the relative risk aversion coefficient. It is optimal for levered individuals to take more conservative investment positions even if their risk aversion coefficient is low. This finding is consistent with the results in Aiyagari and Gertler (1999). These authors show that the existence of the margin constraint increases the traders' effective degree of risk aversion, since they wish to avoid having to unload assets at discount prices. Furthermore, how effectively risk averse traders act depends on how close they are to violating their respective margin constraints.

\subsubsection{Optimal financial leverage}

This section assesses the effect of optimally choosing the individual's leverage position on the optimal allocation of assets to the investment portfolio. The business cycle is proxied by the growth on the industrial production index. Table 4 reports a negative parameter estimate for $\kappa$ across model specifications that is more precisely estimated for longer investment horizons. These results provide substantive empirical evidence of a negative relationship between the business cycle and the individual's financial leverage position. According to these estimates, an improvement in the economy described by growth on industrial production is reflected in a lower value of the leverage coefficient. Similarly, 
an impoverishment in economic conditions, reflected in negative growth in industrial activity, implies a higher value of the leverage coefficient. These results suggest that individuals increase leverage during economic recessions and decrease it during economic expansions. Figure 4 plots the dynamics of the leverage parameter, $\eta_{t}$, and the debt ratio, $f\left(\eta_{t}\right)=\eta_{t} /\left(1+\eta_{t}\right)$, over time. Large values of these quantities match very well NBER recession periods.

The results in Table 4 also show that the optimal allocation to the $\mathrm{S} \& \mathrm{P} 500$ is positively related to the one-month average of the excess stock and bond returns across investment horizons. The optimal allocation to the $\mathrm{S} \& \mathrm{P} 500$ for the investment horizon $K=120$ is also negatively related to the detrended short-term interest rate and positively related to the U.S. credit spread and the momentum variable. In contrast, the optimal allocation to bonds is negatively related to all of the state variables. The test of overidentifying restrictions (24) reports lack of statistical evidence to reject the correct specification of the parametric choices (8) and (13) used to model the allocation to assets in the portfolio. The comparison of the results in Tables 3 and 4 reveal significant differences in the values of the $\lambda$ parameters associated to the S\&P 500 and G0Q0 bond index. In particular, we observe a decrease in the magnitude of the parameter estimates for portfolios constructed using financial leverage.

\section{[Insert Tables 4 to 5 about here]}

We also analyze the effect of the dynamic leverage on the mean asset demands. Table 5 reports the mean optimal portfolio weights allocated to the S\&P 500 and G0Q0 bond index under different investment horizons $(K=12,60$ and 120) and a relative risk aversion coefficient $\gamma=5$. This is done by comparing the base scenario characterized by absence of borrowing with the model reporting dynamic leverage positions. The differences between the optimal portfolio weights corresponding to the unconstrained investor and the constrained investor with leverage dynamics described by (13) are illustrated in Figure 5 for $K=120$ and $\gamma=5$. The unconstrained optimal portfolio weights are very volatile and react very aggressively to changes of the investment opportunity set. Individuals facing highly levered financial positions cannot reach these positions and their optimal allocation assigns a lower fraction of wealth to the risky assets, limiting, therefore, the size of the short position on 
the one-month Treasury bill rate. Table 6 confirms this empirical observation by noting that the average optimal portfolio weight allocated to the stock and bond indices is reduced by $35 \%$ and $45 \%$, respectively, under financial leverage. Interestingly, this reduction is more pronounced the shorter the individual's investment horizon.

[Insert Figures 4 to 5 about here]

Table 6 and 7 also illustrate the effect of financial leverage on the coefficients that establish the optimal asset allocation for the long-term investment horizon, $K=120$, for different values of the relative risk aversion coefficient. Thus, Table 6 reports the parameter estimates of an investor with leverage parameter modeled by (13) and relative risk aversion coefficients $\gamma=2,5$ and 40 . The test of overidentifying restrictions (24) reports lack of statistical evidence (p-values larger than 0.30) to reject the correct specification of (8) and (13) with the only exception of the model that considers $\gamma=2$, that yields a p-value of zero. The $\lambda$ parameter estimates show a negative correlation with the risk aversion coefficient $\gamma$. This empirical finding reveals the existence of a negative relationship between the degree of investor's risk aversion and the responsiveness of the individual's optimal portfolio to changes in the information set. This pattern is also observed for the optimal choice of leverage, reflected on the $\kappa$ parameter, as $\gamma$ decreases. More specifically, decreases in the coefficient of relative risk aversion are accompanied by stronger reactions of the individual's leverage position to business cycle dynamics.

\section{[Insert Tables 6 to 7 about here]}

Table 7 reports the mean optimal portfolio weights allocated to the S\&P 500 and G0Q0 bond indices for $K=120$ and $\gamma=2,5$ and 40. The purpose of this exercise is to compare the base scenario characterized by an investment portfolio fully funded with individual's equity with the scenario characterized by portfolios partially funded through debt. Table 7 shows that the mean optimal portfolio weights allocated to both financial indices diminish significantly for increasing values of the individual's leverage position. 


\section{Conclusions}

An important contributor to the strong economic growth witnessed in the last forty years has been the development of sound credit markets providing access to funding to individuals. The easier access to credit has favoured consumption and investment. In this paper, we have studied the influence that the possibility of financial leverage may have in the construction of optimal portfolios for individuals with multiperiod investment horizons. To do this, we have applied a GMM estimation procedure applied over a multiperiod set of Euler equations.

The conclusions of this study are threefold. First, financial leverage limits the reaction of investors to changes in the investment opportunity set. Second, we observe that individuals that can optimize their financial leverage position choose countercyclical policies: increase their leverage during economic recessions and decrease it during economic expansions. Third, optimal portfolio weights and financial leverage are negatively related to the degree of investor's risk aversion and positively related to the investment horizon.

These conclusions are supported by the findings of our empirical application to a portfolio of stocks, bonds and cash. In particular, we uncover the existence of a monotonically decreasing relationship between the magnitude of the parameters driving the optimal portfolio weights and the amount of leverage allowed in the individual's financial position. This finding implies that the long-term optimal asset allocation of individuals with highly levered financial positions is less responsive to variations in market conditions and suggests that the existence of leverage increases the traders' effective degree of risk aversion by increasing the share of wealth invested on the risk-free asset. Furthermore, how effectively risk averse traders act also depends on the individual's relative risk aversion coefficient and the investment horizon characterizing the multiperiod objective function. 


\section{References}

[1] Aït-Sahalia, Y., and Brandt, M.W. (2001). Variable Selection for Portfolio Choice. Journal of Finance 56, 1297-1351.

[2] Aiyagari, S.R. and Gertler, M. (1999). "Overreaction of Asset Prices in General Equilibrium. Review of Economic Dynamics 2, 3-35.

[3] Brandt, M.W. (1999). Estimating portfolio and consumption choice: A conditional Euer equations approach. Journal of Finance 54, 1609-1646.

[4] Brandt, M., and Santa Clara, P. (2006). Dynamic Portfolio Selection by Augmenting the Asset Space. Journal of Finance 61, 2187-2217.

[5] Brandt, M., Santa Clara, P., and Valkanov, R. (2009). Parametric portfolio policies exploiting the characteristics in the cross section of equity returns. Review of Financial Studies 22, 3411-3447.

[6] Brennan, M., Schwartz, E., and Lagnado, R. (1997). Strategic asset allocation. Journal of Economic Dynamics and Control 21, 1377-1403.

[7] Brennan, M., Schwartz, E., and Lagnado, R. (1999). The use of treasury bill futures in strategic asset allocation programs. In: Ziemba, W.T., Mulvey, J.M. (Eds.), World Wide Asset and Liability Modeling. Cambridge University Press, Cambridge, pp. 205-228.

[8] Brunnermeier, M.K., and Sannikov, Y. (2014). The I Theory of Money. Unpublished manuscript.

[9] Campbell, J.Y. (1991). A variance decomposition for stock returns. Economic Journal 101, 157179.

[10] Campbell, J. Y. (2006). Household Finance. Journal of Finance 61, 4, 1553-1604.

[11] Campbell, J. Y., and Viceira, L. M. (1999). Consumption and portfolio decisions when expected returns are time varying. Quarterly Journal of Economics 114, 433-495. 
[12] Campbell, J. Y., and Viceira, L. M. (2001). Who should buy long-term bonds? American Economic Review 91, 99-127.

[13] Campbell, J. Y., and Viceira, L. M. (2002). Strategic Asset Allocation: Portfolio Choice for Long-Term Investors (Oxford University Press, New York).

[14] Campbell, J. Y., Chan, Y., and Viceira, L. M. (2003). A multivariate model of strategic asset allocation. Journal of Financial Economics 67, 41-80.

[15] Cochrane, J. H. (1996). A Cross-Sectional Test of an Investment-Based Asset Pricing Model. The Journal of Political Economy 104, 572-621.

[16] Fama, E. F., and French, K.R. (1989). Business conditions and expected returns on stocks and bonds. Journal of Financial Economics 25, 23-49.

[17] Hansen, L. (1982). Large sample properties of generalized method of moments estimators. Econometrica 50, 1029-1054.

[18] He, Z., and Krishnamurthy, A. (2013). Intermediary Asset Pricing. American Economic Review 103, (2), 732-770.

[19] Schularick, M., and Taylor, A. (2012). Credit Booms Gone Bust: Monetary Policy, Leverage Cycles, and Financial Crises, 1870-2008. American Economic Review 102, 1029-1061, 
TABLES AND FIGURES

Table 1: Sample statistics

\begin{tabular}{|l|c|c|c|c|c|}
\hline & Mean & Volatility & ratio & Skewness & Kurtosis \\
\hline$R_{\text {S\&P500 }}^{e}$ & 0.0266 & 0.131 & 0.21 & -1.12 & 4.88 \\
\hline$R_{\text {Bonds }}^{e}$ & 0.0290 & 0.0566 & 0.51 & 0.15 & 2.17 \\
\hline$r_{f}$ & 0.0183 & 0.021 & & 0.38 & 3.16 \\
\hline
\end{tabular}

This table presents the sample statistics of the excess stock returns $\left(R_{S \& P 500}^{e}\right)$, bond excess returns $\left(R_{\text {Bonds }}^{e}\right)$ and short-term ex-post real interest rates $\left(\mathrm{r}_{\mathrm{f}}\right)$. The sample data covers the period January 1980 to December 2010. The return horizon is one month. The mean and the volatility are expressed in annualized terms. 
Table 2: Seemingly unrelated regression estimation of the excess stock return, bond excess return and short-term ex-post real interest rates.

\begin{tabular}{|c|c|c|c|c|c|}
\hline$R_{S \& P 500}^{e}$ & $\mathrm{~T}_{\mathrm{b}}$ & Def & Trend & ARP & $R^{2}$ \\
\hline$\beta_{R_{S \& P 500}^{e}}$ & -0.23 & -0.13 & -0.02 & 1.19 & 0.10 \\
\hline$p$-value & 0.25 & 0.51 & 0.90 & 0.00 & \\
\hline$R_{\text {Bonds }}^{e}$ & $\mathrm{~T}_{\mathrm{b}}$ & Def & Trend & ARP & $R^{2}$ \\
\hline$\beta_{\text {Bonds }}$ & -0.02 & -0.04 & -0.01 & -0.02 & 0.03 \\
\hline$p$-value & 0.82 & 0.62 & 0.15 & 0.01 & \\
\hline$r_{f}$ & $\mathrm{~T}_{\mathrm{b}}$ & Def & Trend & ARP & $R^{2}$ \\
\hline$\beta_{r_{f}}$ & -0.05 & 0.25 & 0.19 & -0.08 & 0.06 \\
\hline$p$-value & 0.33 & 0.00 & 0.00 & 0.11 & \\
\hline
\end{tabular}

This table presents the estimates of the seemingly unrelated regression estimation (SURE) of the excess stock return $\left(R_{S \& P 500}^{e}\right)$, bond excess return $\left(R_{\text {Bonds }}^{e}\right)$ and short-term ex-post real interest rates $\left(r_{f}\right)$, using as explanatory variables the state variables: the detrended short-term interest rate $\left(\mathrm{T}_{\mathrm{b}}\right)$, the U.S. credit spread (Def), the S\&P 500 trend (Trend) and the one-month average of the excess stock and bond returns (ARP). We use monthly data from January 1980 to December 2010. 
Table 3: Optimal asset allocation with no leverage.

\begin{tabular}{|c|c|c|c|c|c|c|c|c|c|c|c|}
\hline$\gamma=5$ & $\mathrm{~K}=12$ & & & & $K=60$ & & & & $\mathrm{~K}=120$ & & \\
\hline & $\alpha_{S \& P 500}$ & & $\alpha_{\text {Bonds }}$ & & $\alpha_{S \& P 500}$ & & $\alpha_{\text {Bonds }}$ & & $\alpha_{S \& P 500}$ & & $\alpha_{\text {Bonds }}$ \\
\hline$\lambda_{\mathrm{Tb}}$ & -0.23 & $\lambda_{\mathrm{Tb}}$ & -1.06 & $\lambda_{\mathrm{Tb}}$ & -0.30 & $\lambda_{\mathrm{Tb}}$ & -1.28 & $\lambda_{\mathrm{Tb}}$ & -1.20 & $\lambda_{\mathrm{Tb}}$ & -0.92 \\
\hline t-stat & $(-1.05)$ & t-stat & $(-2.63)$ & t-stat & $(-1.42)$ & t-stat & $(-4.49)$ & t-stat & $(-2.81)$ & t-stat & $(-2.21)$ \\
\hline$\lambda_{\text {Def }}$ & 0.21 & $\lambda_{\text {Def }}$ & -4.08 & $\lambda_{\text {Def }}$ & -0.18 & $\lambda_{\text {Def }}$ & -3.74 & $\lambda_{\text {Def }}$ & -0.35 & $\lambda_{\text {Def }}$ & -3.62 \\
\hline t-stat & $(0.88)$ & t-stat & $(-8.52)$ & $t$-stat & $(-0.73)$ & t-stat & $(-9.02)$ & t-stat & $(-0.70)$ & t-stat & $(-5.02)$ \\
\hline$\lambda_{\text {Trend }}$ & -0.18 & $\lambda_{\text {Trend }}$ & -3.10 & $\lambda_{\text {Trend }}$ & -0.14 & $\lambda_{\text {Trend }}$ & -3.59 & $\lambda_{\text {Trend }}$ & 0.54 & $\lambda_{\text {Trend }}$ & -3.97 \\
\hline t-stat & $(-0.75)$ & t-stat & $(-5.62)$ & t-stat & $(-0.67)$ & t-stat & $(-8.30)$ & t-stat & (1.06) & t-stat & $(-6.16)$ \\
\hline$\lambda_{\mathrm{ARP}}$ & 3.15 & $\lambda_{\mathrm{ARP}}$ & -1.40 & $\lambda_{\mathrm{ARP}}$ & 3.95 & $\lambda_{\mathrm{ARP}}$ & -1.09 & $\lambda_{\mathrm{ARP}}$ & 4.31 & $\lambda_{\mathrm{ARP}}$ & -1.96 \\
\hline t-stat & (7.63) & t-stat & $(-2.44)$ & t-stat & (13.73) & t-stat & $(-2.93)$ & t-stat & (5.44) & t-stat & $(-3.37)$ \\
\hline$\chi^{2}$ & 68.96 & & & $\chi^{2}$ & 56.94 & & & $\chi^{2}$ & 46.85 & & \\
\hline p-value & 0.01 & & & $p$-value & 0.04 & & & $p$-value & 0.21 & & \\
\hline
\end{tabular}

This table reports the estimates of the optimal asset allocation under absence of financial leverage. The investment horizon is $K=120$. The investment portfolio is comprised by the S\&P 500 index, the G0Q0 bond index and the one-month U.S. Treasury bill rate. The optimal portfolio rule is specified in equation (8) and optimized for a CRRA utility function assuming $\gamma=5$, and a value of $\beta=0.95$. We consider the following state variables that drive the timevarying investment opportunity set: the detrended short-term interest rate $\left(T_{b}\right)$, the U.S. credit spread (Def), the S\&P 500 trend (Trend) and the one-month average of the excess stock and bond returns (ARP). We use monthly data from January 1980 to December 2010. 
Table 4: Optimal strategic asset allocation using an optimal financial leverage position.

\begin{tabular}{|c|c|c|c|c|c|c|c|c|c|c|c|}
\hline$\gamma=5$ & $\mathrm{~K}=12$ & & & & $\mathrm{~K}=60$ & & & & $K=120$ & & \\
\hline & $\alpha_{S \& P 500}$ & & $\alpha_{\text {Bonds }}$ & & $\alpha_{S \& P 500}$ & & $\alpha_{\text {Bonds }}$ & & $\alpha_{S \& P 500}$ & & $\alpha_{\text {Bonds }}$ \\
\hline$\lambda_{\mathrm{Tb}}$ & 0.02 & $\lambda_{\mathrm{Tb}}$ & -0.56 & $\lambda_{\mathrm{Tb}}$ & -0.23 & $\lambda_{\mathrm{Tb}}$ & -0.36 & $\lambda_{\mathrm{Tb}}$ & -0.88 & $\lambda_{\mathrm{Tb}}$ & -0.13 \\
\hline t-stat & $(0.21)$ & t-stat & $(-2.47)$ & $t$-stat & $(-1.32)$ & t-stat & $(-1.40)$ & t-stat & $(-5.94)$ & t-stat & $(-0.54)$ \\
\hline$\lambda_{\text {Def }}$ & 0.15 & $\lambda_{\text {Def }}$ & -2.00 & $\lambda_{\text {Def }}$ & -0.03 & $\lambda_{\text {Def }}$ & -2.21 & $\lambda_{\text {Def }}$ & -0.29 & $\lambda_{\text {Def }}$ & -1.66 \\
\hline t-stat & (1.62) & t-stat & $(-8.39)$ & $t$-stat & $(-0.20)$ & t-stat & $(-8.06)$ & t-stat & $(-2.03)$ & t-stat & $(-3.83)$ \\
\hline$\lambda_{\text {Trend }}$ & -0.11 & $\lambda_{\text {Trend }}$ & -1.55 & $\lambda_{\text {Trend }}$ & 0.06 & $\lambda_{\text {Trend }}$ & -2.04 & $\lambda_{\text {Trend }}$ & 0.82 & $\lambda_{\text {Trend }}$ & -2.31 \\
\hline t-stat & $(-0.95)$ & t-stat & $(-5.54)$ & $t$-stat & $(0.38)$ & t-stat & $(-5.08)$ & $t$-stat & $(6.07)$ & t-stat & $(-6.00)$ \\
\hline$\lambda_{\mathrm{ARP}}$ & 1.75 & $\lambda_{\mathrm{ARP}}$ & -0.76 & $\lambda_{\mathrm{ARP}}$ & 2.30 & $\lambda_{\mathrm{ARP}}$ & -0.43 & $\lambda_{\mathrm{ARP}}$ & 2.81 & $\lambda_{\mathrm{ARP}}$ & -0.88 \\
\hline t-stat & (12.56) & t-stat & $(-2.46)$ & $t$-stat & (9.56) & t-stat & $(-1.58)$ & t-stat & (17.56) & t-stat & $(-3.17)$ \\
\hline$\kappa$ & -0.08 & & & & -0.11 & & & & -0.27 & & \\
\hline t-stat & $(-1.94)$ & & & & $(-1.96)$ & & & & $(-3.74)$ & & \\
\hline$\chi^{2}$ & 58.87 & & & $\chi^{2}$ & 59.15 & & & $\chi^{2}$ & 48 & & \\
\hline p-value & 0.07 & & & $p$-value & 0.06 & & & p-value & 0.31 & & \\
\hline
\end{tabular}

This table reports the estimates of the optimal asset allocation for different optimal choices of financial leverage driven by the parametric function (13) relating growth in the industrial production index and financial leverage. The investment horizon is $K=12,60,120$. The investment portfolio is comprised by the S\&P500 index, the G0Q0 bond index and the onemonth U.S. Treasury bill rate. The optimal portfolio rule is specified in equation (8) and optimized for a CRRA utility function assuming $\gamma=5$, given a value of $\beta=0.95$. We consider the following state variables that drive the time-varying investment opportunity set: the detrended short-term interest rate $\left(\mathrm{T}_{\mathrm{b}}\right)$, the U.S. credit spread (Def), the S\&P 500 trend (Trend) and the one-month average of the excess stock and bond returns (ARP). We use monthly data from January 1980 to December 2010. 
Table 5: Mean asset demands for different investment horizons. No financial leverage vs. a timevarying financial leverage position.

\begin{tabular}{|l|c|c|c|c|c|c|}
\hline & \multicolumn{2}{|c|}{ Absence of financial leverage } & \multicolumn{3}{c|}{ Optimal financial leverage } \\
\hline$\gamma=5$ & $\alpha_{S \& P 500}$ & $\alpha_{\text {Bonds }}$ & $\alpha_{T B}$ & $\alpha_{S \& P 500}$ & $\alpha_{\text {Bonds }}$ & $\alpha_{T B}$ \\
\hline$K=12$ & 1.36 & 3.07 & -3.42 & 0.75 & 1.34 & -1.09 \\
$K=60$ & 1.50 & 2.33 & -2.83 & 0.95 & 1.24 & -1.19 \\
$K=120$ & 0.82 & 3.40 & -3.22 & 0.63 & 2.20 & -1.83 \\
\hline
\end{tabular}

This table reports the mean optimal allocation in percentage points to stocks, bonds and cash of an individual with an investment horizon of 12, 60 and 120 months. The left panel reports the case corresponding to absence of financial leverage. The right panel reports the case of optimally chosen financial leverage using the parametric function (13) relating growth in the industrial production index and financial leverage. The optimal parametric portfolio policy rule is specified in equation (8). We consider the following state variables that drive the timevarying investment opportunity set: the detrended short-term interest rate $\left(\mathrm{T}_{\mathrm{b}}\right)$, the U.S. credit spread (Def), the S\&P 500 trend (Trend) and the one-month average of the excess stock and bond returns (ARP). We use monthly data from January 1980 to December 2010. 
Table 6: Optimal asset allocation for different degrees of risk aversion using an optimal choice of financial leverage.

\begin{tabular}{|c|c|c|c|c|c|c|c|c|c|c|c|}
\hline \multicolumn{4}{|c|}{$\gamma=2$} & \multicolumn{4}{|c|}{$\gamma=5$} & \multicolumn{4}{|c|}{$\gamma=40$} \\
\hline & $\alpha_{S \& P 500}$ & & $\alpha_{\text {Bonds }}$ & & $\alpha_{S \& P 500}$ & & $\alpha_{\text {Bonds }}$ & & $\alpha_{S \& P 500}$ & & $\alpha_{\text {Bonds }}$ \\
\hline$\lambda_{\mathrm{Tb}}$ & -1.34 & $\lambda_{\mathrm{Tb}}$ & 0.14 & $\lambda_{\mathrm{Tb}}$ & -0.88 & $\lambda_{\mathrm{Tb}}$ & -0.13 & $\lambda_{\mathrm{Tb}}$ & -0.10 & $\lambda_{\mathrm{Tb}}$ & -0.06 \\
\hline$t$-stat & $(-5.69)$ & t-stat & $(0.30)$ & t-stat & $(-5.94)$ & t-stat & $(-0.54)$ & t-stat & $(-3.80)$ & t-stat & $(-1.28)$ \\
\hline$\lambda_{\text {Def }}$ & 0.47 & $\lambda_{\text {Def }}$ & -4.75 & $\lambda_{\text {Def }}$ & -0.29 & $\lambda_{\text {Def }}$ & -1.66 & $\lambda_{\text {Def }}$ & -0.03 & $\lambda_{\text {Def }}$ & -0.22 \\
\hline t-stat & (2.01) & t-stat & $(-9.10)$ & t-stat & $(-2.03)$ & t-stat & $(-3.83)$ & t-stat & $(-1.66)$ & $t$-stat & $(-3.75)$ \\
\hline$\lambda_{\text {Trend }}$ & 0.66 & $\lambda_{\text {Trend }}$ & -4.50 & $\lambda_{\text {Trend }}$ & 0.82 & $\lambda_{\text {Trend }}$ & -2.31 & $\lambda_{\text {Trend }}$ & 0.10 & $\lambda_{\text {Trend }}$ & -0.36 \\
\hline$t$-stat & (2.83) & $t$-stat & $(-8.09)$ & t-stat & (6.07) & t-stat & $(-6.00)$ & t-stat & $(1.76)$ & $t$-stat & $(-5.05)$ \\
\hline$\lambda_{\mathrm{ARP}}$ & 5.78 & $\lambda_{\mathrm{ARP}}$ & -0.36 & $\lambda_{\mathrm{ARP}}$ & 2.81 & $\lambda_{\mathrm{ARP}}$ & -0.88 & $\lambda_{\mathrm{ARP}}$ & 0.36 & $\lambda_{\mathrm{ARP}}$ & -0.11 \\
\hline$t$-stat & (22) & t-stat & $(-0.79)$ & t-stat & (17.56) & t-stat & $(-3.17)$ & t-stat & (8.57) & t-stat & $(-1.36)$ \\
\hline$\kappa$ & -0.13 & & & & -0.27 & & & & -0.37 & & \\
\hline t-stat & $(-4.07)$ & & & & $(-3.74)$ & & & & $(-3.66)$ & & \\
\hline$\chi^{2}$ & 86.77 & & & $\chi^{2}$ & 48 & & & $\chi^{2}$ & 43.80 & & \\
\hline p-value & 0.00 & & & p-value & 0.31 & & & $p$-value & 0.48 & & \\
\hline
\end{tabular}

This table reports the estimates of the optimal asset allocation for different optimal choices of financial leverage driven by the parametric function (13) relating growth in the industrial production index and financial leverage. The investment horizon is $K=120$. The investment portfolio is comprised by the S\&P500 index, the G0Q0 bond index and the one-month U.S. Treasury bill rate. The optimal portfolio rule is specified in equation (8) and optimized for a CRRA utility function given different values of $\gamma=2,5$ and 40 , and a value of $\beta=0.95$. We consider the following state variables that drive the time-varying investment opportunity set: the detrended short-term interest rate $\left(\mathrm{T}_{\mathrm{b}}\right)$, the U.S. credit spread (Def), the S\&P 500 trend (Trend) and the one-month average of the excess stock and bond returns (ARP). We use monthly data from January 1980 to December 2010. 
Table 7: Mean asset demands for different values of relative risk aversion. No financial leverage vs. a time-varying financial leverage position.

\begin{tabular}{|l|c|c|c|c|c|c|}
\hline & \multicolumn{3}{|c|}{ Absence of financial leverage } & \multicolumn{3}{c|}{ Optimal financial leverage } \\
\hline$K=120$ & $\alpha_{S \& P 500}$ & $\alpha_{\text {Bonds }}$ & $\alpha_{T B}$ & $\alpha_{S \& P 500}$ & $\alpha_{\text {Bonds }}$ & $\alpha_{T B}$ \\
\hline$\gamma=2$ & 2.26 & 8.01 & -9.27 & 1.73 & 3.34 & -4.07 \\
$\gamma=5$ & 0.82 & 3.40 & -3.22 & 0.95 & 1.24 & -1.19 \\
$\gamma=40$ & 0.09 & 0.32 & 0.59 & 0.06 & 0.28 & 0.66 \\
\hline
\end{tabular}

This table reports the mean optimal allocation in percentage points to stocks, bonds and cash of an individual with an investment horizon of 120 months. The left panel reports the case corresponding to absence of financial leverage. The right panel reports the case of optimally chosen financial leverage using the parametric function (13) relating growth in the industrial production index and financial leverage. The optimal parametric portfolio policy rule is specified in equation (8). We consider the following state variables that drive the time-varying investment opportunity set: the detrended short-term interest rate $\left(\mathrm{T}_{\mathrm{b}}\right)$, the U.S. credit spread (Def), the S\&P 500 trend (Trend) and the one-month average of the excess stock and bond returns (ARP). We use monthly data from January 1980 to December 2010. 
Figure 1: Parameter $\lambda$ under a constant leverage position and different relative risk aversion coefficients.

\section{S\&P 500.}

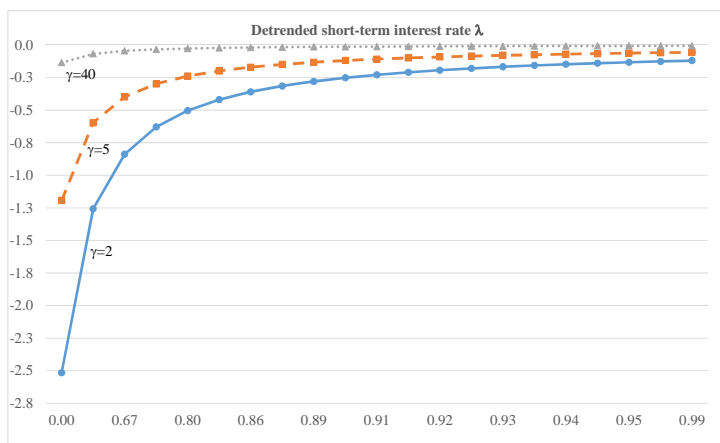

$\mathbf{f}(\eta)$
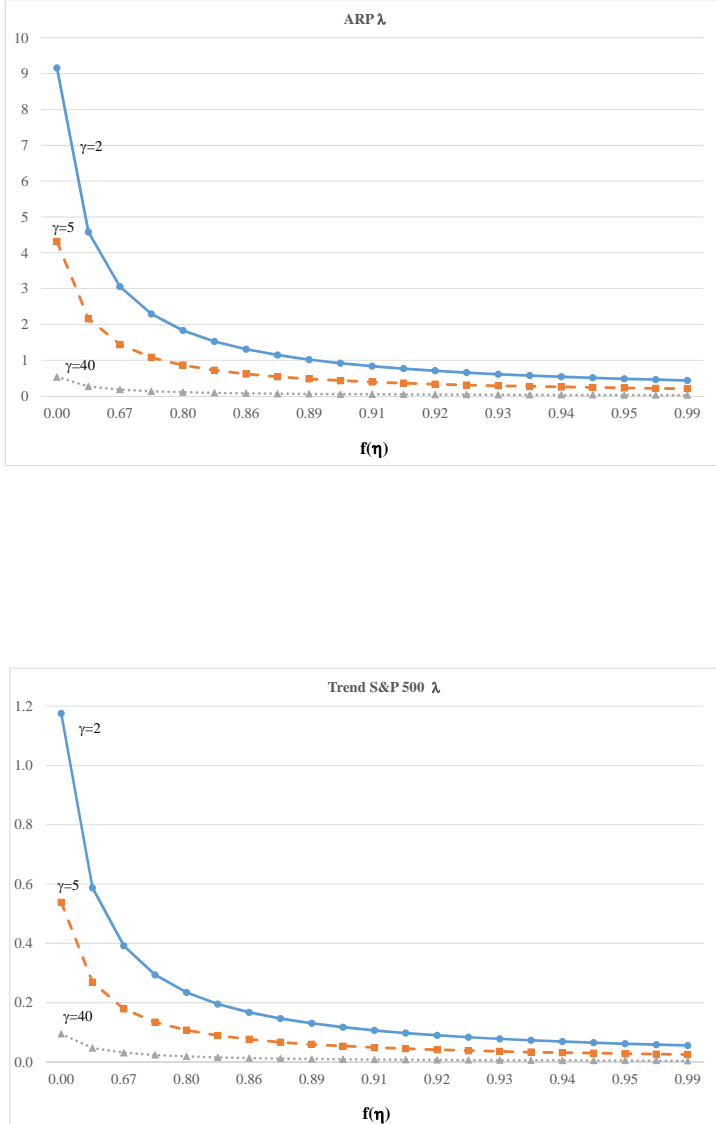

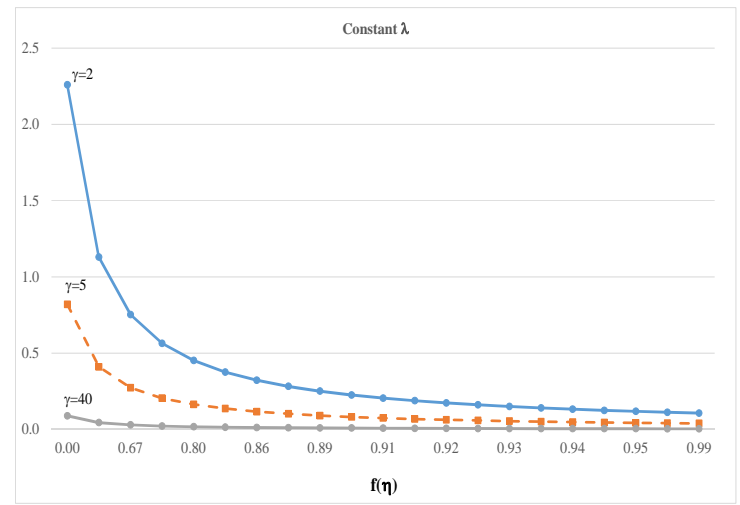




\section{G0Q0 Index.}
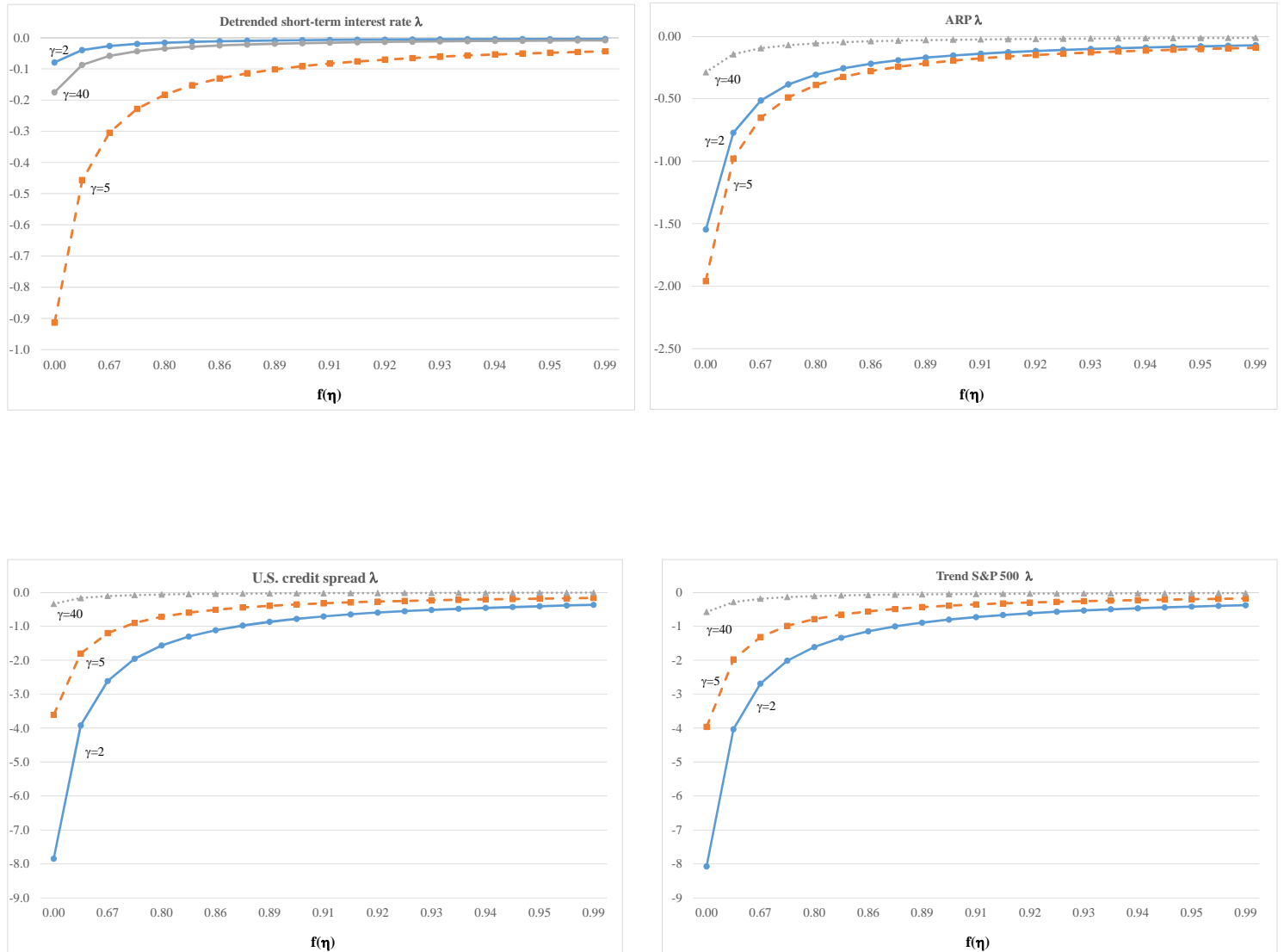

$f(\eta)$

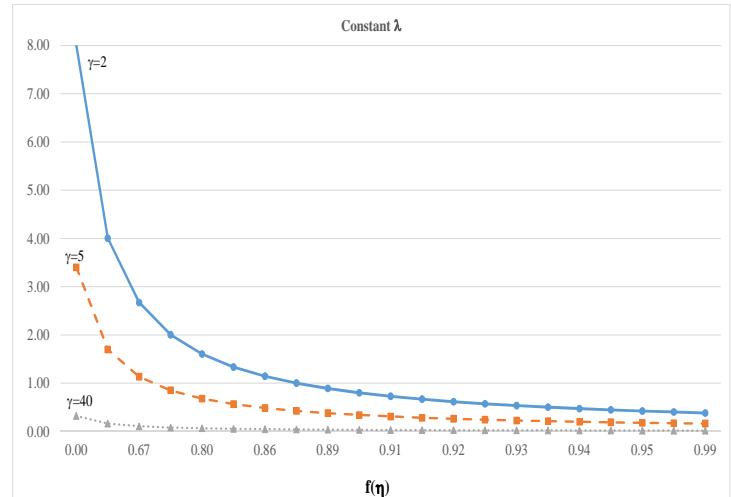

The different charts report the sensitivity of the vector of parameters $\lambda$ in equation (8) to changes in the magnitude of the financial leverage position faced by the investor. The figure represents the debt/financial wealth ratio, defined by the function $f(\eta)$ in expression (4). We consider an investor that can allocate her wealth among stocks, bonds and the one-month Treasury bill rate. The optimal portfolio rule is optimized for a CRRA utility function using $\gamma=5,20$ and 40 , a value of $\beta=0.95$ and an investment horizon $K=120$. The time-varying investment opportunity set is driven by these state variables: the detrended short-term interest rate (Tb), the U.S. credit spread (Def), the S\&P 500 trend (Trend) and the one-month average of the excess stock and bond returns (ARP). We use monthly data from January 1980 to December 2010. 
Figure 2: Optimal portfolio allocation for different values of financial leverage $\eta$.

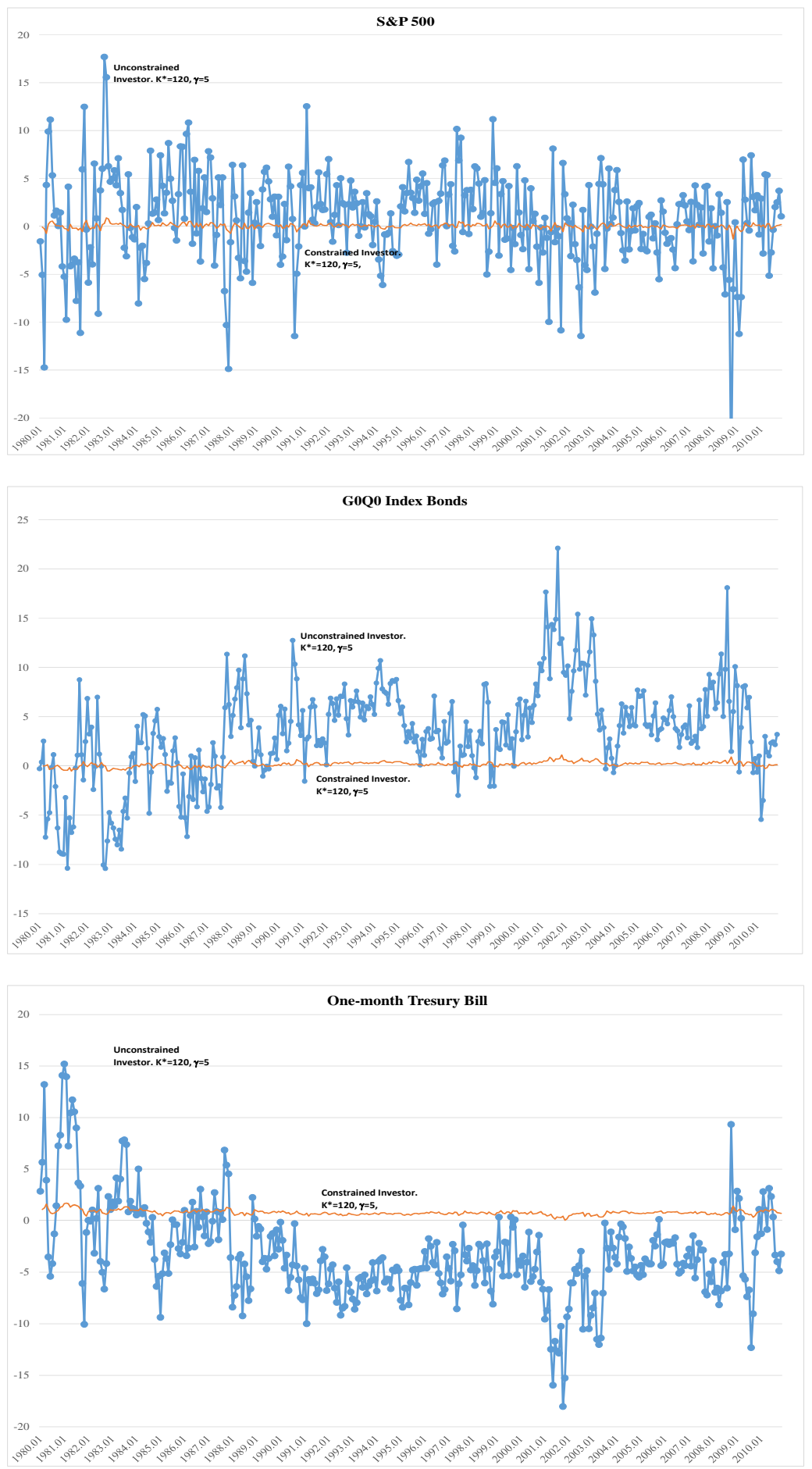

The figures plot the optimal portfolio weights as defined in equation (8) of the investor without financial leverage and the levered investor whose debt ratio in each period is determined by the ratio $f(\eta)=0.95$. We consider an investor that can allocate her wealth among stocks, bonds and the one-month Treasury bill rate. The optimal portfolio rule is optimized for a CRRA utility function using $\gamma=5$, a value of $\beta=0.95$ and an investment time horizon $K=120$. The time-varying investment opportunity set is driven by these state variables: the detrended short-term interest rate (Tb), the U.S. credit spread (Def), the S\&P 500 trend (Trend) and the one-month average of the excess stock and bond returns (ARP). We use monthly data from January 1980 to December 2010. 
Figure 3: Parameter $\lambda$ under constant financial leverage for different investment horizons.

$\underline{\text { S\&P } 500 .}$
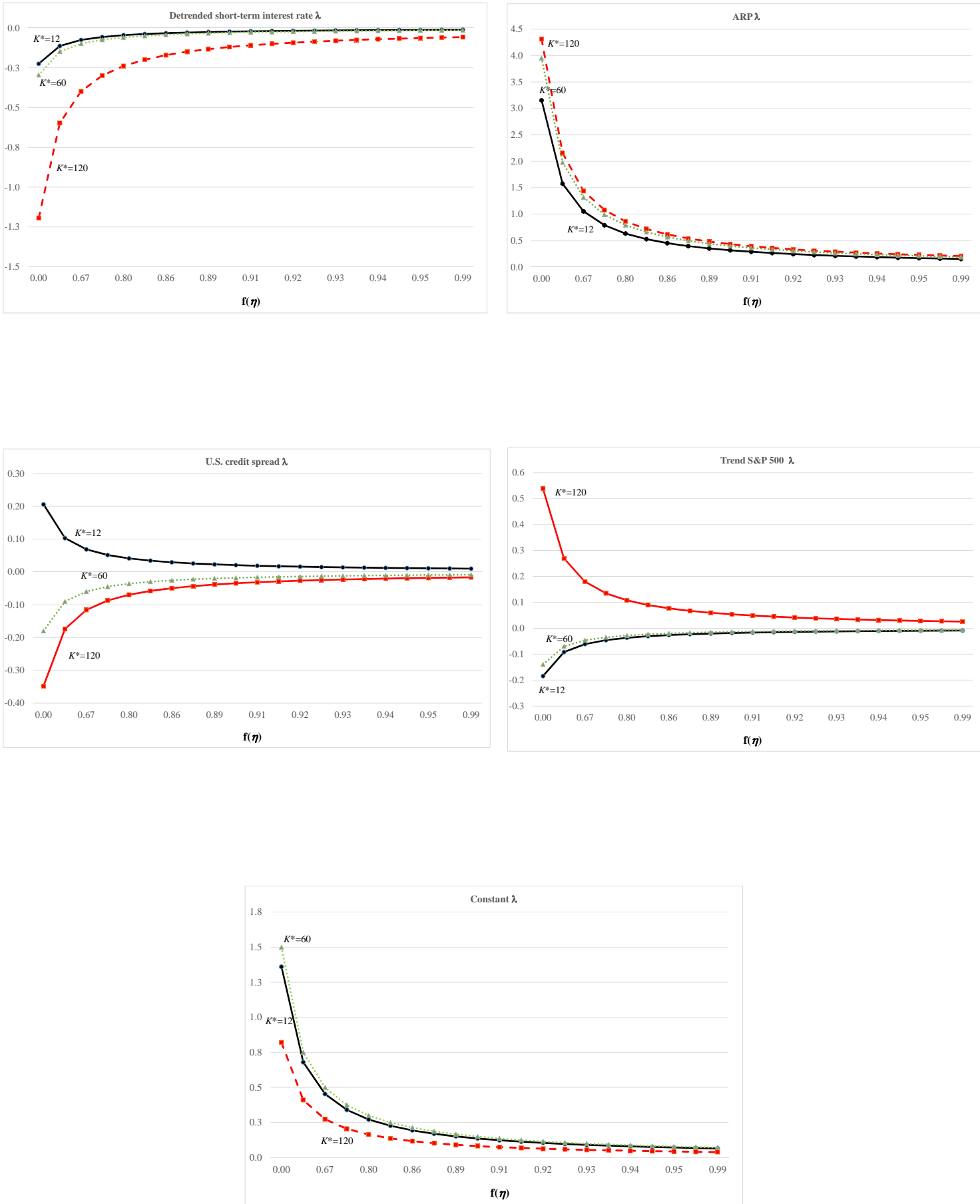


\section{G0Q0 Index.}
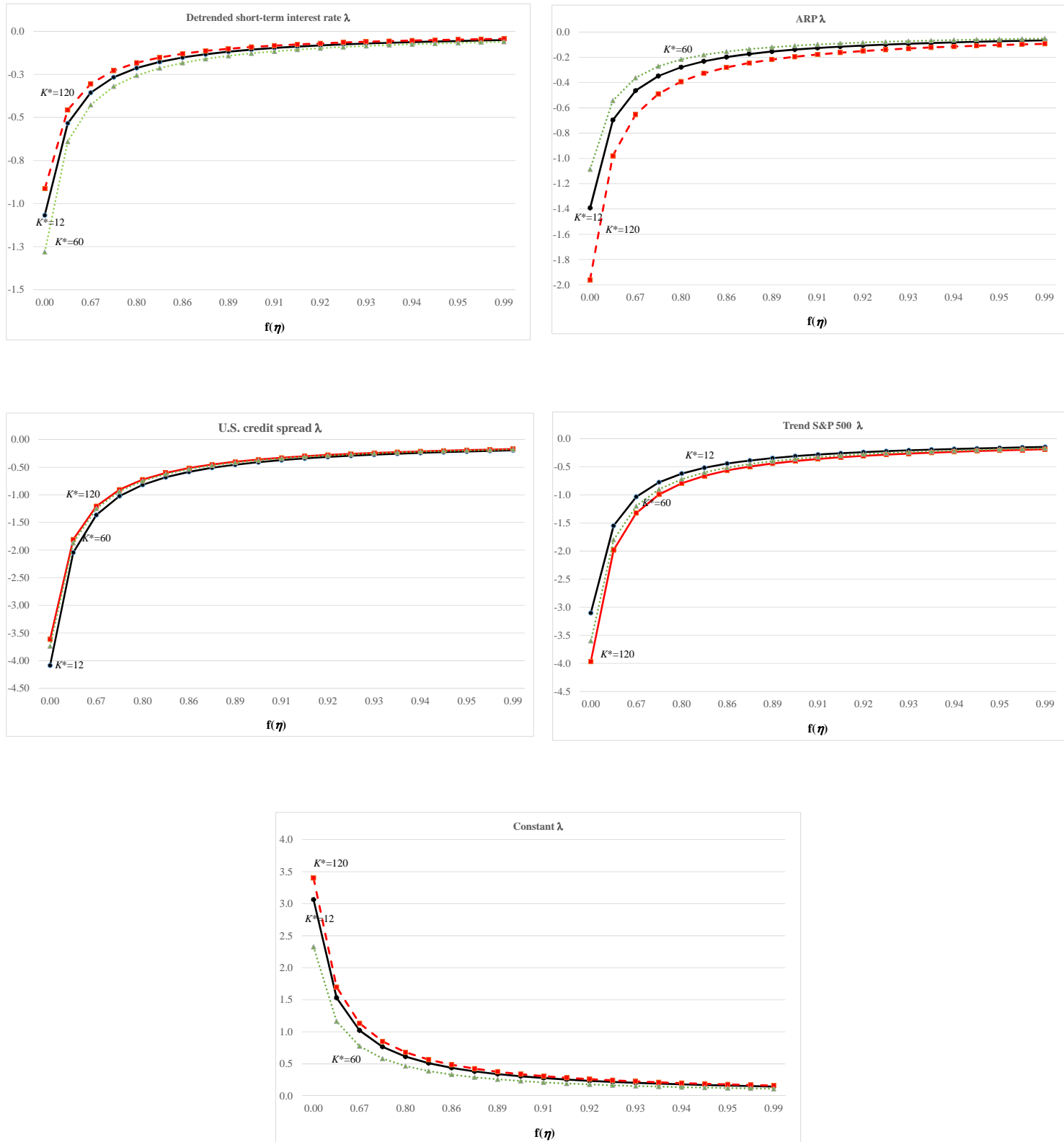

The different charts report the sensitivity of the vector of parameters $\lambda$ in equation (8) to changes in the magnitude of the financial leverage position faced by the investor. The figure represents the debt/financial wealth ratio, defined by the function $f(\eta)$ in expression (4). We consider an investor that can allocate her wealth among stocks, bonds and the one-month Treasury bill rate. The optimal portfolio rule is optimized for a CRRA utility function using $\gamma=5$, a value of $\beta=0.95$ and investment horizons $K=12,60$ and 120 . The time-varying investment opportunity set is driven by these state variables: the detrended short-term interest rate (Tb), the U.S. credit spread (Def), the S\&P 500 trend (Trend) and the one-month average of the excess stock and bond returns (ARP). We use monthly data from January 1980 to December 2010. 
Figure 4. Dynamics of the optimal choice of financial leverage over time as a function of growth on the industrial production index.

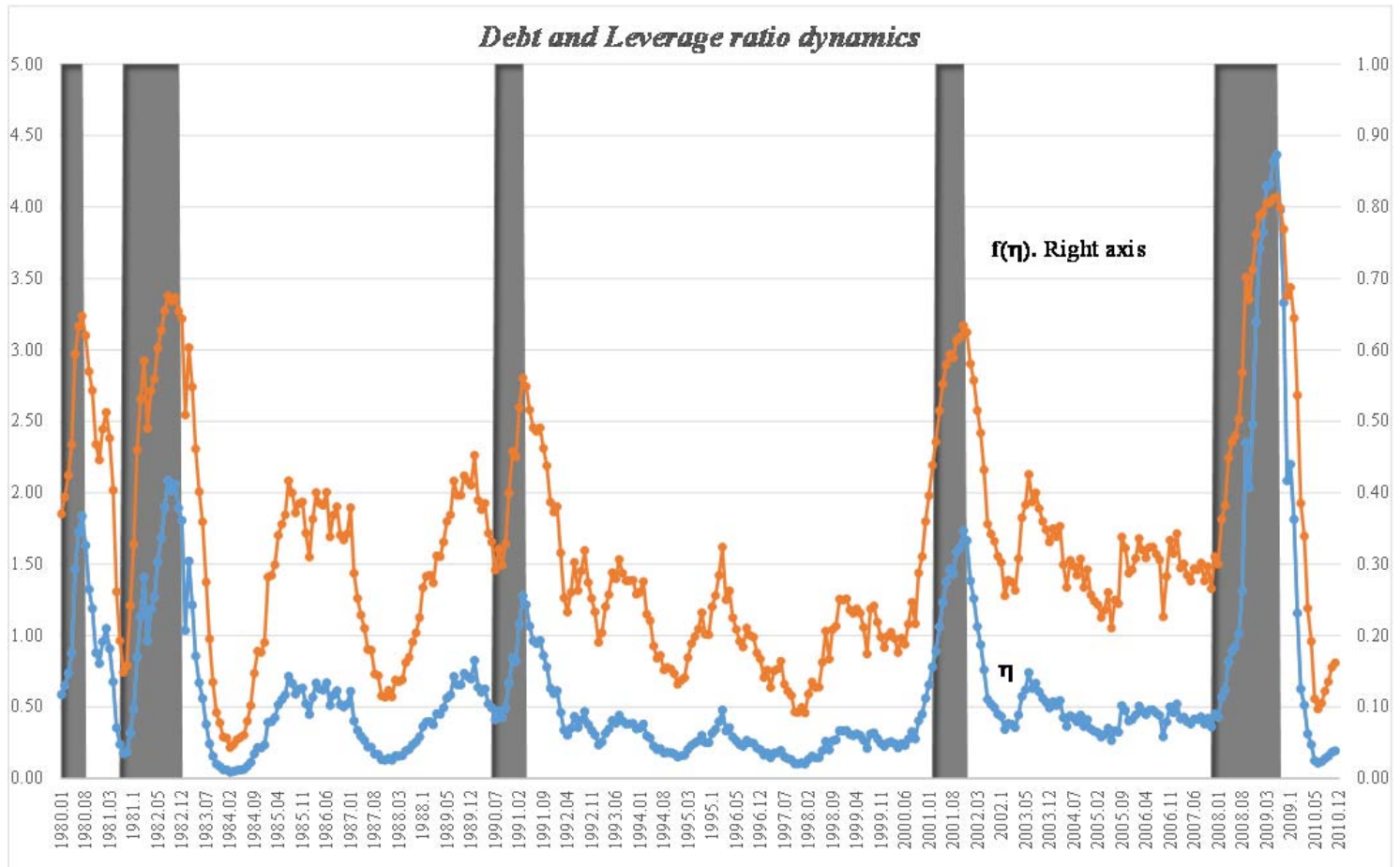

The figure plots the estimated financial leverage obtained from expression (13) and the corresponding ratio of debt over financial wealth, $f(\eta)$, introduced in (4). We consider an investor that can allocate her wealth among stocks, bonds and the one-month Treasury bill rate. The optimal portfolio rule is specified in equation (8) and optimized for a CRRA utility function using $\gamma=5$, a value of $\beta=0.95$ and an investment horizon $K=120$. The time-varying investment opportunity set is driven by the following state variables: the detrended short-term interest rate (Tb), the U.S. credit spread (Def), the S\&P 500 trend (Trend) and the one-month average of the excess stock and bond returns (ARP). We use monthly data from January 1980 to December 2010. 


\section{Figure 5: Optimal portfolio allocation for the optimal choice of dynamic leverage $\eta$.}

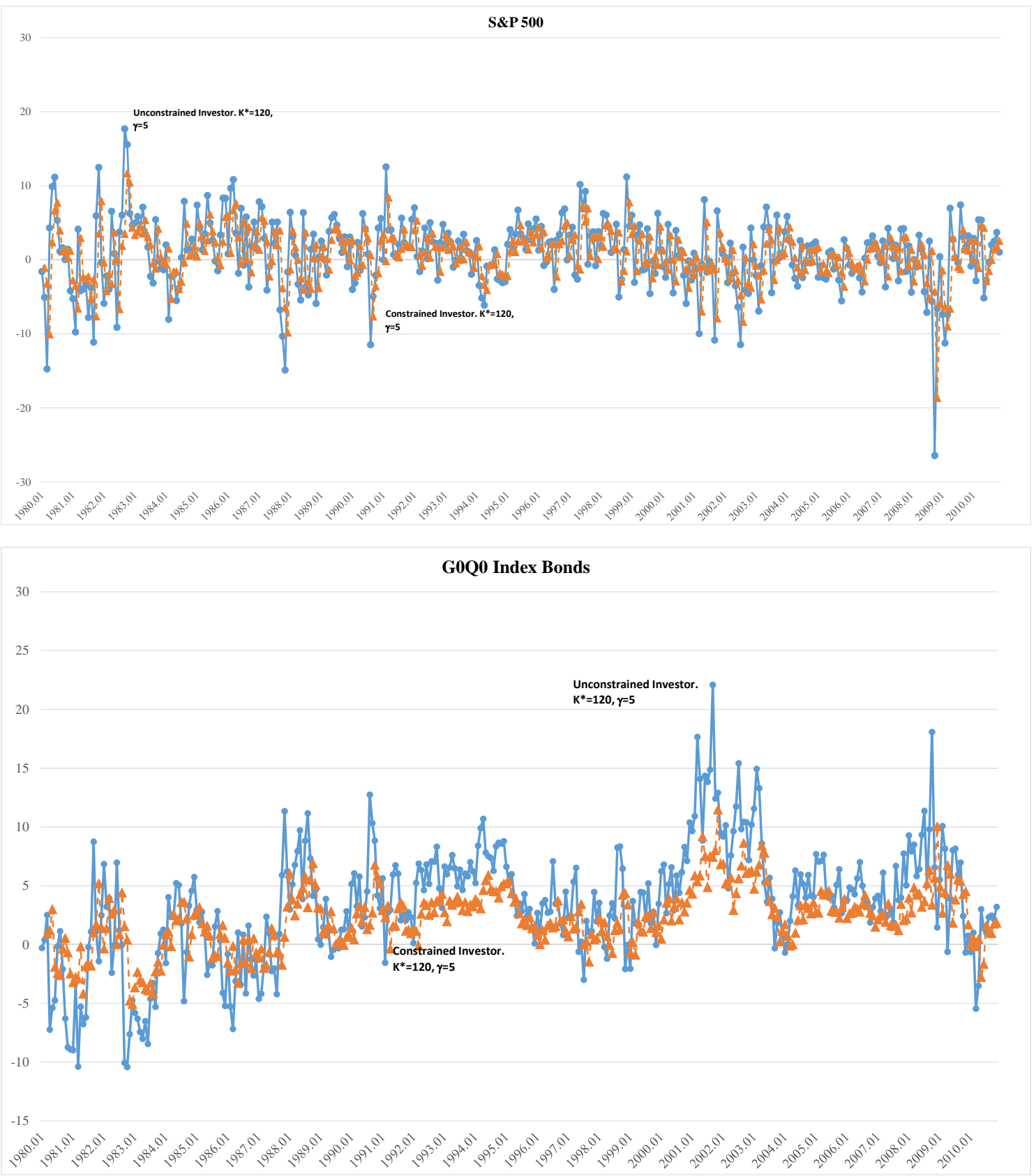

The figures plot the optimal portfolio weights as defined in equation (8) of the investor without financial leverage and the levered investor choosing optimally its financial leverage position. The relationship between the business cycle (growth in industrial production index) and the individual's financial leverage position is assumed to be driven by expression (13). We consider an investor that can allocate her wealth among stocks, bonds and the one-month Treasury bill rate. The optimal portfolio rule is optimized for a CRRA utility function using $\gamma=5$, a value of $\beta=0.95$ and an investment time horizon $K=120$. The time-varying investment opportunity set is driven by these state variables: the detrended short-term interest rate (Tb), the U.S. credit spread (Def), the S\&P 500 trend (Trend) and the one-month average of the excess stock and bond returns (ARP). We use monthly data from January 1980 to December 2010. 